\title{
Acceptability of a text message-based intervention for obesity prevention in infants from Hawai'i and Puerto Rico WIC
}

\author{
Cheryl L. K. Gibby ${ }^{1}$, Cristina Palacios ${ }^{2}$, Maribel Campos ${ }^{3}$, Rafael E. Graulau ${ }^{4}$ and Jinan Banna ${ }^{1 *}$ (D)
}

\begin{abstract}
Background: Low-income and minority children are at increased risk for obesity. Text messaging offers advantages for delivering education, but few studies have assessed the acceptability of text messaging in interventions aimed at preventing excessive weight gain in infants. This study investigated the acceptability of a text message-based intervention for prevention of excessive weight gain in infants from Hawai'i and Puerto Rico WIC clinics.

Methods: The four-month text message based intervention designed to improve infant feeding practices and reduce excessive weight gain was a randomized controlled trial that included mothers with infants ages $0-2$ months at baseline. Participants in the intervention arm received 18 text messages (1/week) promoting breastfeeding and appropriate complementary feeding. Acceptability of the intervention was assessed from participant retention, satisfaction, and evidence of behavior change in a sequential multimethod approach, quantitatively from questions sent via text and qualitatively during the in-person exit interview. The final analysis included 80 mother-infant pairs from the intervention arm.
\end{abstract}

Results: When asked about messages liked and disliked the most, the majority of responses via text indicated that they liked all messages. From the qualitative analyses, most participants reported that all messages were useful and that the messages led them to make changes in the way they fed their infants. Participant retention was good at 78.4\%.

Conclusions: The intervention was acceptable to participants based upon participant retention, measures of satisfaction, and reports of behavior change. Results may inform development of mobile health programs for minority childhood obesity prevention.

Trial registration: ClinicalTrials.gov Identifier; NCT02903186; September 16, 2016.

Keywords: Text message, Low income, Childhood obesity, Infants, WIC, Breastfeeding, Complementary feeding, Randomized controlled trial, Mobile health, Minority

\section{Background}

Childhood obesity is a serious public health problem which increases the risk of developing other chronic disease later in life, such as diabetes, cancer and cardiovascular disease [1]. The comorbidities associated with childhood obesity affect almost every system in the body, including the endocrine, gastrointestinal, pulmonary, cardiovascular and musculoskeletal systems [1]. Low-income

\footnotetext{
* Correspondence: jcbanna@hawaii.edu

'Department of Human Nutrition, Food and Animal Sciences, College of Tropical Agriculture and Human Resources, University of Hawai'i at Mānoa, Agricultural Sciences 216, 1955 East-West Rd, Honolulu, HI 96822, USA Full list of author information is available at the end of the article
}

and minority children are especially at risk for obesity [2], with Hispanic children having increased odds of rapid infancy weight gain [3] and Native Hawaiian or other Pacific Islander (NHOPI) children having higher weight early in life [4]. In the US, $40 \%$ of low-income one-year-olds and $30 \%$ of two to five-year-olds participating in the Special Supplemental Nutrition Program for Women, Infants, and Children (WIC) were overweight or obese in 2014 [5, 6]. Early intervention to support optimal weight gain, therefore, may be especially beneficial in these groups.

Breastfeeding is protective against obesity $[7,8]$, with more protection conferred as exclusivity and duration of breastfeeding increases [9]. Early discontinuation of 
breastfeeding and early introduction of solid foods is associated with excessive weight gain $[3,10]$. Currently, the US breastfeeding rate at six months is below the Healthy People 2020 goal of $60.6 \%$ [11], and in some locations the rate is especially low, such as in Puerto Rico at $38.1 \%$ [12]. There is a continued need to promote and support appropriate breastfeeding practices.

Infant health studies using text messaging to deliver infant feeding information have reported significantly lower prevalence of overweight and obesity in infants at six months old [13] and improved exclusive breastfeeding duration [14]. Other studies have used text messaging to improve infant weight [15] and to improve adherence to the infant immunization schedule [16]. However, there have not been many text message-based studies aimed at preventing childhood obesity.

Text message-based interventions for health promotion and disease prevention deliver educational information, reminders, questions, tips, and other correspondence via text messages. Mobile phones are useful tools for health interventions because of their increasing popularity, ease of usability, and people's tendency to always carry them [17]. Mobile health (mHealth) programs are potentially more effective than traditional face-to-face interventions, which are more labor intensive, time consuming, and expensive [18]. Minority groups, those with lower household income, and those with lower levels of completed education were reported to text more than other groups [19], indicating that text message-based interventions may be most effective in these groups.

Mobile technology may also help to increase participant retention in studies. For example, a health behavior study reported that children in the text message group had better participant retention (72\%) in comparison to the nontechnology (39\%) and control (50\%) groups, and significantly greater adherence (43\%) to self-monitoring in comparison to the non-technology (19\%) groups [20]. Some nutrition studies utilizing text messaging have reported excellent participant retention rates ranging from 80 to 97\% [21-23]. Participant retention has been commonly used in studies to assess acceptability [24].

Assessing acceptability is a necessary component in determining the effectiveness of an intervention [24]. For example, a study on acceptability and program development for a mobile phone depression prevention intervention for adolescents reported findings regarding participation rates, how well participants liked the messages, usefulness of the messages, and aspects of behavioral change [25]. Text message-based interventions have been shown to be well accepted in many nutrition studies [20, 26-28]; however, not many infant health studies have assessed acceptability of the interventions. Assessing acceptability of text messagebased interventions contributes to the improvement of mHealth intervention designs.
The objective of this study was to determine the acceptability of a text message-based intervention for obesity prevention in infants from lower socioeconomic backgrounds in Hawai'i and Puerto Rico using qualitative and quantitative methods to assess participant retention, satisfaction, and evidence of behavior change. Major themes regarding the usefulness of the text messages and how participants were influenced to change behaviors were investigated, and messages liked the most and least were determined.

\section{Methods \\ Participants}

The four-month text message-based intervention was designed to improve infant feeding practices and reduce excessive infant weight gain. Mother-infant pairs in WIC in Hawaii i and Puerto Rico were recruited. Infants were $0-2$ months at baseline. Eligibility criteria for mothers/caregivers included the following: at least 18 years old, owned a mobile phone with unrestricted texting capabilities, responsible for caring for the infant, willing to complete the entire study, and able to read. Additionally, inclusion criteria required the infant to have been no more than two months old at baseline, to have been born after 37 weeks of gestation, to be on a normal diet and free from disabilities that hinder movement, and to have had birthweight at or between the 10th and 90th percentiles as indicated by the World Health Organization (WHO) growth charts [29]. Study procedures were approved by the institutional review boards at the University of Hawai'i at Mānoa and the University of Puerto Rico, Medical Sciences Campus. Written informed consent was obtained prior to data collection. Additional details about methods and outcomes for the trial have been published elsewhere [30,31].

\section{Intervention design}

To send and receive messages, a third-party web-based text messaging platform was used as the Internet gateway. We ensured consistency in the messages as they were developed in culturally appropriate English and Spanish, for the selected target populations. Messages in Hawaii i were sent in English and messages in Puerto Rico were delivered in Spanish. Prior to the study, some of the messages were pre-tested with five women in Puerto Rico, who all reported that the utility and frequency of messages were excellent [32]. Details regarding intervention design have been published elsewhere [31].

\section{Intervention implementation}

Participants' cell phones were registered in the webbased text messaging platform at baseline.

Over the course of four months, participants received 18 text messages sent on varying days and times, at a 
frequency of one message per week. Participants were informed they could send comments or questions back if desired. Approximately the first half of the intervention group messages focused on reinforcing WIC breastfeeding messages, with the remainder of messages focused on complementary feeding practices such as preventing overfeeding, delaying introduction of solid foods, and reducing juice consumption. Information on the control messages has been published previously [31].

Follow-up visits were conducted in person four months after the participant's baseline visit [31]. Measures from the baseline visit were repeated and participants in the intervention group completed an interview during which qualitative data regarding acceptability of the study was collected.

\section{Satisfaction}

During the intervention but separate from the main text messages, participants in the intervention arm were sent seven short quantitative and qualitative questions approximately every other week, starting after the second week, and were told that these text messages required a response. Two questions, "Which text message did you like the most so far?" and "Which text message did you like the least so far?" were analyzed. Responses to the other quantitative questions were reported elsewhere [30].

\section{Evidence of behavior change}

At the follow-up visit, they also completed a qualitative interview regarding helpfulness of the messages, problems with receiving messages, ways in which receiving the messages influenced or changed feeding practices, and overall feelings about receiving the messages. Interviewers were trained in techniques and protocol by the principal investigators. Responses were handwritten by the interviewers and later transcribed. Participants were asked six openended questions and were encouraged to elaborate on answers. Responses to the following three qualitative questions were analyzed: "Thinking back on the messages you were sent, which text messages were the most useful to you in feeding your infant? Why?", "Thinking back on the messages you were sent, which text messages were the least useful to you in feeding your infant? Why", and "Were there any messages that led you to feed your baby in a certain way, or make changes in what you might normally do? If so, which ones (text messages) were these, and how did they influence the way you feed your baby?" Responses to the other three qualitative questions are reported elsewhere [30].

\section{Participant retention}

Eighty participants from the intervention group completed the follow-up visit and qualitative interview.
Twenty-two participants from the intervention group were lost to follow up: Hawai i $(n=15)$ and Puerto Rico $(n=7)$. Details explaining reasons participants were lost to follow-up were published previously [29].

\section{Data analyses}

For baseline characteristics, descriptive statistics were presented using frequencies and percentages, or using means and standard deviations. Chi-squares tests, Fisher's exact tests, and two-sample t-tests were conducted to investigate the differences in characteristics between the final analysis group and the group that was lost to follow-up. For all analyses, a $p$-value of $<0.05$ was considered statistically significant. Analyses were performed using SAS University Edition (SAS Institute Inc., Cary, NC).

Content analysis was used to analyze qualitative data and report on themes from participant responses. Transcribed interviews were entered into NVivo Pro for Windows (QSR International, Inc., Burlington, MA) by two coders, one in Hawai' $\mathrm{i}$ and one in Puerto Rico. A shared codebook was developed prior to coding and was updated during coding. Inter-rater reliability was tested prior to coding using four transcripts until a kappa value of 0.95 was achieved between coders [33]. Each coder completed coding for all transcripts at his/her site. Then, coders independently identified themes by examining frequencies of codes. Via conference call, results were compared and discussed until agreement was reached.

\section{Results}

Thirty-seven participants (46.3\%) from Hawai'i and 43 participants (53.8\%) from Puerto Rico were included in the final analysis. Characteristics of the intervention group, final analysis group, and group that was lost to follow-up are shown in Table 1. Comparing participants in the final analysis group $(n=80)$ with those who did not complete the study $(n=22)$, no statistically significant differences were found for site, pregravid body mass index (BMI), education, race/ethnicity (other than White), parity, pregnancy complications (such as diabetes, hypertension, or anemia), infant gender, being upto-date with vaccines, taking vitamins while breastfeeding, maternal age (as a continuous variable), gestational age at birth, or gestational weight gain. Women who were White $(p=0.04)$ were less likely to have been lost to follow-up. In comparison to women in age group 2531 years, women aged 18-24 years and women aged 32 years and older were more likely to be lost to follow-up $(p=0.02)$.

\section{Participant retention}

Participant retention was $78.4 \%$. In Hawai $i$, the rate was $71.2 \%$, and in Puerto Rico, the rate was $86 \%$. 
Table 1 Distribution of select maternal and infant characteristics, n (\%), for the groups in the text message-based intervention acceptability study

\begin{tabular}{|c|c|c|c|c|}
\hline & Total intervention $(n=102)$ & Final analysis $(n=80)$ & Lost to follow-up $(n=22)$ & $p$-value \\
\hline Site & & & & $0.068^{a}$ \\
\hline Hawai'i & $52(51.0)$ & $37(46.3)$ & $15(68.2)$ & \\
\hline Puerto Rico & $50(49.0)$ & $43(53.8)$ & $7(31.8)$ & \\
\hline \multicolumn{5}{|l|}{ Maternal factors } \\
\hline Pregravid BMI (mean [SD]) & $26.6[6.9]$ & $26.7[7.1]$ & $26.4[6.0]$ & $0.873^{d}$ \\
\hline Age (mean $[S D]$ ) & $26.9[5.3]$ & $27.0[5.0]$ & $26.5[6.4]$ & $0.688^{d}$ \\
\hline Age group & & & & $0.024^{b *}$ \\
\hline 18-24 years & $42(41.2)$ & $30(37.5)$ & $12(54.6)$ & \\
\hline $25-31$ years & $38(37.3)$ & $35(43.8)$ & $3(13.6)$ & \\
\hline $32-39$ years & $22(21.6)$ & $15(18.8)$ & $7(31.8)$ & \\
\hline \multicolumn{5}{|l|}{ Racec/ethnicity } \\
\hline Hispanic & $62(62.0)$ & $52(65.0)$ & $10(50.0)$ & $0.216^{\mathrm{a}}$ \\
\hline Native Hawaiian or Other Pacific Islander & $22(21.6)$ & $17(21.3)$ & $5(22.7)$ & $0.881^{\mathrm{a}}$ \\
\hline Asian & $22(21.6)$ & $16(20.0)$ & $6(27.3)$ & $0.463^{\mathrm{a}}$ \\
\hline American Indian or Alaska Native & $5(4.9)$ & $5(6.3)$ & $0(0)$ & $0.582^{b}$ \\
\hline Black or African American & $15(14.7)$ & $14(17.5)$ & $1(4.6)$ & $0.181^{b}$ \\
\hline White & $34(33.3)$ & $31(38.8)$ & $3(13.6)$ & $0.039^{\mathrm{b} *}$ \\
\hline Education & & & & $0.449^{b}$ \\
\hline Less than college & $49(49.5)$ & $38(47.5)$ & $11(57.9)$ & \\
\hline Some college & $22(22.2)$ & $20(25.0)$ & $2(10.5)$ & \\
\hline College degree or higher & $28(28.3)$ & $22(27.5)$ & $6(31.6)$ & \\
\hline Parity & & & & $0.126^{b}$ \\
\hline 1 & $41(40.2)$ & $28(35.0)$ & $13(59.1)$ & \\
\hline 2 & $36(35.3)$ & $32(40.0)$ & $4(18.2)$ & \\
\hline 3 & $15(14.7)$ & $11(13.8)$ & $4(18.2)$ & \\
\hline 4 or more & $10(9.8)$ & $9(11.3)$ & $1(4.6)$ & \\
\hline Use of prenatal vitamins & $97(95.1)$ & $78(97.5)$ & 19 (86.4) & $0.066^{\mathrm{b}}$ \\
\hline Pregnancy complications & $43(42.2)$ & $32(40.0)$ & $11(50.0)$ & $0.400^{\mathrm{a}}$ \\
\hline Took vitamins while breastfeeding & $58(56.9)$ & $47(58.8)$ & $11(50.0)$ & $0.463^{\mathrm{a}}$ \\
\hline Gestational age (weeks; mean [SD]) & $39.0[1.1]$ & $39.1[1.1]$ & $38.8[1.1]$ & $0.426^{d}$ \\
\hline Gestational weight gain (lb; mean [SD]) & $27.7[11.2]$ & $27.6[11.1]$ & $28.5[12.1]$ & $0.749^{d}$ \\
\hline \multicolumn{5}{|l|}{ Infant factors } \\
\hline Male & $51(50.0)$ & $39(48.8)$ & $12(54.6)$ & $0.630^{\mathrm{a}}$ \\
\hline Female & $51(50.0)$ & $41(51.3)$ & $10(45.5)$ & \\
\hline Up-to-date with vaccinations & $87(85.3)$ & $68(85.0)$ & 19 (86.4) & $1.00^{\mathrm{b}}$ \\
\hline
\end{tabular}

Note: Column percentages; $\mathrm{p}$-value represents final analysis vs lost to follow-up;

${ }^{*} p<0.05 ;{ }^{a}$ Analysis by Chi-square test; ${ }^{b}$ Analysis by Fisher's exact test; ${ }^{C}$ Includes all races for mixed participants; ${ }^{\mathrm{d}}$ Analysis by t-test, pooled

\section{Satisfaction}

Results from text messaged questions regarding which messages participants liked the most and the least are reported in Table 2 and Table 3, respectively. Participants responded via text message, and most indicated that they had no preference in topic as they liked all messages the most $(n=8)$. Thereafter, participants in Hawai'i most enjoyed the text messages about offering breastmilk in a bottle or cup $(n=2)$ and breastfeeding often during growth spurts $(n=2)$, while participants in Puerto Rico most enjoyed the educational information about starting $(n=7)$ and implementing $(n=4)$ solid 
Table 2 Responses from participants in week 14 regarding which message they liked the most in the text message-based intervention

\begin{tabular}{|c|c|c|c|}
\hline $\begin{array}{l}\text { Week } \\
\text { delivered }\end{array}$ & Message & $\begin{array}{l}\text { Number of participants: } \\
\text { Puerto Rico }(n=15)\end{array}$ & $\begin{array}{l}\text { Number of } \\
\text { participants: Hawai'i } \\
(n=17)\end{array}$ \\
\hline 2 & $\begin{array}{l}\text { When breastfeeding, make sure the nipple and the area around is inside baby's } \\
\text { mouth. If baby eats from the tips, they will crack. Always correct the position. }\end{array}$ & 1 & \\
\hline 3 & $\begin{array}{l}\text { Breastfeeding is the best way to feed your baby, but it may be hard. Put your baby to } \\
\text { your breast and you will have more milk. Ask for help. }\end{array}$ & & 1 \\
\hline 6 & $\begin{array}{l}\text { Breastfeed your baby from the same breast until it feels empty. That way, your baby } \\
\text { gets the fat that comes at the end and will be full longer. }\end{array}$ & & 1 \\
\hline 8 & $\begin{array}{l}\text { Your milk is the best food for baby for the first } 6 \text { months of life. If you cannot put your } \\
\text { baby directly to your breast, you can give it in a bottle or cup. }\end{array}$ & & 2 \\
\hline 8 & $\begin{array}{l}\text { You can tell if you have enough milk by counting wet diapers. Your baby should have } \\
6 \text { or more wet diapers every day after the } 4 \text { th day of birth. }\end{array}$ & & 1 \\
\hline 9 & $\begin{array}{l}\text { Babies have growth spurts and want to breastfeed often, which increases hunger. } \\
\text { Your baby will drink more to increase your milk for } 3 \text { days. This is normal. }\end{array}$ & & 2 \\
\hline 10 & $\begin{array}{l}\text { If you give milk in a bottle, do not add other foods such as baby cereal or baby food. } \\
\text { If your baby seems full, do not force him/her to finish it. }\end{array}$ & 1 & 1 \\
\hline 13 & $\begin{array}{l}\text { Prepare your milk stock by extracting milk at the end of every feeding and put it in } \\
\text { the fridge in a clean bottle. At the end of the day you will have } 2-3 \mathrm{oz} \text {. }\end{array}$ & 1 & 1 \\
\hline 14 & $\begin{array}{l}\text { Do not put your baby to sleep with the bottle or cup. The milk residue can lead to } \\
\text { cavities and to excess weight. }\end{array}$ & & 1 \\
\hline 15 & $\begin{array}{l}\text { Your baby is ready to eat when he/she sits on his/her own, opens his/her mouth, } \\
\text { chews and leans toward foods. Wait until } 6 \text { months to start feeding other foods. }\end{array}$ & 7 & \\
\hline 16 & $\begin{array}{l}\text { When your baby is } 6 \text { months, you can give meat, cereals with iron, or vegetables } \\
\text { (puree), } 1 \text { at a time and using a spoon. Wait } 3 \text { days before giving a new food. }\end{array}$ & 4 & \\
\hline NA & All messages & 1 & 7 \\
\hline
\end{tabular}

Note: NA Not applicable

Table 3 Responses from participants in week 16 regarding which message they liked the least in the text message-based intervention

\begin{tabular}{|c|c|c|c|}
\hline $\begin{array}{l}\text { Week } \\
\text { delivered }\end{array}$ & Message & $\begin{array}{l}\text { Number of participants: } \\
\text { Puerto Rico }(n=9)\end{array}$ & $\begin{array}{l}\text { Number of } \\
\text { participants: Hawai'i } \\
(n=11)\end{array}$ \\
\hline 3 & $\begin{array}{l}\text { To start breastfeeding again, ask for help. You only can give your milk if you put your } \\
\text { baby to your breast often to make milk. }\end{array}$ & 1 & \\
\hline 7 & $\begin{array}{l}\text { While breastfeeding, you do not need to eat a special diet or beverage, you only need } \\
\text { to be hydrated. Drink 8-10 glasses of water every day. }\end{array}$ & & 1 \\
\hline 11 & $\begin{array}{l}\text { Feed your baby when he/she moves his/her lips, sucks his/her hands and turns his/her } \\
\text { head searching for the breast. Crying does not always mean hunger. }\end{array}$ & 1 & \\
\hline 12 & $\begin{array}{l}\text { If you need to work or study, extract milk every } 2-3 \mathrm{~h} \text { to keep up your milk } \\
\text { production. There are laws that protect you to do this. }\end{array}$ & & 1 \\
\hline 13 & $\begin{array}{l}\text { Prepare your milk stock by extracting milk at the end of every feeding and put it in } \\
\text { the fridge in a clean bottle. At the end of the day you will have } 2-3 \mathrm{oz} \text {. }\end{array}$ & 1 & \\
\hline 15 & $\begin{array}{l}\text { Your baby is ready to eat when he/she sits on his/her own, opens his/her mouth, } \\
\text { chews and leans toward foods. Wait until } 6 \text { months to start feeding solid foods. }\end{array}$ & 1 & 1 \\
\hline 18 & $\begin{array}{l}\text { Baby juice has sugar that babies do not need. Instead of juice, give water or fruits } \\
\text { pureed or blended with water. This will help your baby stay healthy. }\end{array}$ & 1 & \\
\hline NA & Like all messages & 4 & 8 \\
\hline
\end{tabular}


food feeding. Most respondents indicated that they liked all messages when asked about which message they liked the least $(n=12)$.

Results from in-person interview questions on acceptability with exemplifying quotations are presented in Tables 4, 5 and 6 . Themes are reported in order of prominence, according to coding frequencies. Prevalent themes from the qualitative data supported the outcomes of the quantitative observations indicating that the messages were useful and well-liked.

\section{Evidence of behavior change}

Participants expressed that messages that delivered previously unknown information or that were remindful were the most useful in feeding their infants $(n=15)$. Thereafter, participants indicated that all messages $(n=$ 14) and messages about breastfeeding techniques $(n=$ 14) were most useful for feeding.

Regarding which messages were the least useful for feeding, the majority of participants reported that all messages were useful $(n=43)$. Other responses indicated that breastfeeding messages were not useful to participants who were not breastfeeding $(n=12)$ and that breastfeeding messages were not useful if participants already knew the information $(n=10)$.

Most participants reported that the messages led them to make changes in the way they fed their infants, such as by applying correct breastfeeding techniques $(n=12)$, talking to their infant during feedings and observing hunger cues $(n=9)$, and waiting to start solid foods ( $\mathrm{n}=$ 9). However, some participants reported that they made no changes in feeding $(n=24)$.

\section{Discussion}

The intervention acceptability was very good, as indicated by high participant retention, a high rate of liking messages, reports of finding all messages useful in feeding infants and success of messages in changing behaviors.

Sekhon et al. proposed that acceptability is based on emotional and cognitive responses to the intervention and could be assessed prior to or after the intervention [24]. Furthermore, reviews of studies have reported that participant retention or satisfaction measures are often used as proxies for acceptability [24, 34, 35]. Assessed at the end of the intervention, acceptability, as indicated by participant retention (78.4\%), satisfaction, and evidence of behavior change, was good in the current study. Satisfaction was evidenced by most participants liking all the messages and finding all messages useful in feeding their infants. Participants also indicated that the messages were successful in changing behaviors as most participants $(n=56)$ stated that they adjusted their feeding practices. This finding is in line with other text messagebased intervention studies that have reported text messaging is effective in behavioral change [26, 36-38].

According to the theoretical framework of acceptability (TFA), acceptability is represented by seven factors: participants' feelings about the intervention (affective attitude); the amount of effort required to participate (burden); ethicality; extent that benefits, profits, or values are sacrificed to participate (opportunity cost); perceived effectiveness; self-efficacy; and intervention coherence [24]. Based upon this definition of acceptability, the current study has investigated the construct of affective

Table 4 Coding frequencies for most prevalent themes and exemplifying quotations regarding which text messages participants $(n=80)$ felt were the most useful in feeding their infant

\begin{tabular}{|c|c|c|}
\hline $\begin{array}{l}\text { Prevalent themes } \\
\text { and coding } \\
\text { frequencies }\end{array}$ & Explanation of theme & Exemplifying quotation \\
\hline $\begin{array}{l}\text { Most-feeding } \\
\text { knowledge }(H \mathrm{H}=9 \\
\mathrm{PR}=6)\end{array}$ & $\begin{array}{l}\text { Messages informed or reminded participant of feeding facts } \\
\text { and tips. }\end{array}$ & $\begin{array}{l}\text { "Choosing formula with iron was helpful because I didn't } \\
\text { really know much about iron." }\end{array}$ \\
\hline $\begin{array}{l}\text { Most-breastfeeding } \\
\text { knowledge }(H=3 \\
\text { PR }=12)\end{array}$ & $\begin{array}{l}\text { Messages informed or reminded participant of breastfeeding } \\
\text { facts and tips. }\end{array}$ & $\begin{array}{l}\text { "Now I have an 8-year-old son and these are things (about } \\
\text { breastfeeding) I never knew." }\end{array}$ \\
\hline $\begin{array}{l}\text { Most-all }(H I=6, P R= \\
\text { 8) }\end{array}$ & All messages were found useful. & $\begin{array}{l}\text { "Yes, all the information was useful and I replied back to } \\
\text { some of them." }\end{array}$ \\
\hline $\begin{array}{l}\text { Most-breastfeeding } \\
\text { technique }(H I=7 \\
P R=7)\end{array}$ & $\begin{array}{l}\text { Participant gained knowledge of techniques such as proper } \\
\text { positioning, pain management, and milk production. }\end{array}$ & $\begin{array}{l}\text { "I always had a hard time breastfeeding, especially getting } \\
\text { baby latched on. So this message was a good reminder for } \\
\text { latching." }\end{array}$ \\
\hline $\begin{array}{l}\text { Most-breastfeeding } \\
\text { signs }(H I=7, P R=3)\end{array}$ & $\begin{array}{l}\text { Messages informed participant of hunger signs that indicate } \\
\text { when to breastfeed. }\end{array}$ & $\begin{array}{l}\text { "I thought in the beginning that crying meant he was } \\
\text { hungry, so we wasted a lot of milk trying to feed him when } \\
\text { he wasn't hungry." }\end{array}$ \\
\hline $\begin{array}{l}\text { Most-feeding } \\
\text { application }(H \mathrm{H}=8 \\
\mathrm{PR}=1)\end{array}$ & $\begin{array}{l}\text { Messages helped participant apply proper feeding techniques } \\
\text { and information, such as counting diapers and offering foods } \\
\text { with a spoon. }\end{array}$ & $\begin{array}{l}\text { "I used spoon to feed and watched baby's behavior to new } \\
\text { foods like when she goes to rice cereal and opens her } \\
\text { mouth." }\end{array}$ \\
\hline
\end{tabular}


Table 6 Coding frequencies for most prevalent themes and exemplifying quotations regarding how messages changed the way participants $(n=80)$ fed their infant

\begin{tabular}{|c|c|c|}
\hline $\begin{array}{l}\text { Prevalent themes and } \\
\text { coding frequencies }\end{array}$ & Explanation of theme & Exemplifying quotation \\
\hline $\begin{array}{l}\text { Changes-none none } \\
(H \mathrm{H}=7, \mathrm{PR}=8)\end{array}$ & Participant made no changes. & "No, did not change the way I fed my baby." \\
\hline $\begin{array}{l}\text { Changes-breastfeeding } \\
\text { knowledge }(H I=2, P R= \\
\text { 10) }\end{array}$ & $\begin{array}{l}\text { Messages led participant to apply correct } \\
\text { breastfeeding techniques. }\end{array}$ & $\begin{array}{l}\text { "It helped me produce more breast milk with the correct } \\
\text { technique." }\end{array}$ \\
\hline $\begin{array}{l}\text { Changes-feeding talk } \\
\text { gestures }(H \mathrm{I}=6, \mathrm{PR}=3)\end{array}$ & $\begin{array}{l}\text { Participant started talking to baby during feedings and } \\
\text { learned to observe baby's gestures to indicate hunger. }\end{array}$ & $\begin{array}{l}\text { "Knowing crying doesn't always mean hunger helped me pay } \\
\text { more attention to baby's cues." }\end{array}$ \\
\hline $\begin{array}{l}\text { Changes-feeding solid } \\
\text { time }(H \mathrm{H}=3, \mathrm{PR}=6)\end{array}$ & $\begin{array}{l}\text { Participant decided to wait for suggested time to start } \\
\text { feeding infant solid foods. }\end{array}$ & $\begin{array}{l}\text { "Although some people told me to feed solid food to baby, I } \\
\text { waited until 5-6 months." }\end{array}$ \\
\hline $\begin{array}{l}\text { Changes-none already } \\
\text { knew }(H I=6, P R=3)\end{array}$ & $\begin{array}{l}\text { Participant did not make any changes because they } \\
\text { already knew the information. }\end{array}$ & "No, I already knew the information in the messages." \\
\hline $\begin{array}{l}\text { Changes-feeding caries } \\
(H \mathrm{H}=5, \mathrm{PR}=3)\end{array}$ & $\begin{array}{l}\text { Participant stopped putting her infant to sleep with a } \\
\text { bottle. }\end{array}$ & $\begin{array}{l}\text { "The message about putting baby to sleep with a bottle- I was } \\
\text { doing this and then stopped doing it after reading the } \\
\text { message." }\end{array}$ \\
\hline
\end{tabular}

Note: HI Hawai'i, PR Puerto Rico

attitude in responses about liking the messages and the construct of perceived effectiveness in behavioral changes that were made by participants in response to messages. Evidence of acceptability for this intervention which support other constructs of the TFA were reported previously: convenience was cited most as what participants liked about the intervention (burden); most participants reported no problems in participating (selfefficacy and intervention coherence); and participants most frequently reported enjoying the experience (ethicality) [30]. Therefore, the current study offers further evidence of the acceptability of the intervention and presents insight into which messages were most and least useful in feeding.

Improvements could be made to the intervention. For example, future studies may consider only delivering breastfeeding messages to the formula-feeding group during the first several weeks since they were second most cited as the least useful messages for those who were not breastfeeding. Instead, more messages pertaining to formula and solid food feeding may be more useful in this intervention arm. Also, although no participants during the current study restarted breastfeeding, it may be beneficial in future studies to have another set of messages specific for the needs of relactating mothers who decide to start breastfeeding after reading the text messages. At the baseline visit, mothers in the formula group could be informed that they can notify researchers by texting if they start breastfeeding. At that time, mothers would receive messages specific to relactation since their needs differ from women who have not had a break in lactation [39].

As markers of acceptability, satisfaction measures and participant retention may be confounded by other factors, such as incentives or accessibility of the intervention site [24, 34]. Therefore, it may be important to also assess anticipated acceptability prior to the intervention, which would allow researchers to modify aspects of the intervention for greater acceptability and participation [24]. Moreover, conducting assessments before and after the intervention allows for a more comprehensive view of acceptability.

\section{Limitations of the study}

The current study has several limitations. First, while acceptability of the intervention was assessed, the results reported in this publication do not indicate whether or not the intervention does in fact lead to changes in

Table 5 Coding frequencies for most prevalent themes and exemplifying quotations regarding which messages participants $(n=80)$ felt were the least useful in feeding their infant

\begin{tabular}{|c|c|c|}
\hline $\begin{array}{l}\text { Prevalent themes and coding } \\
\text { frequencies }\end{array}$ & Explanation of theme & Exemplifying quotation \\
\hline Least-none $(H \mathrm{I}=25, \mathrm{PR}=18)$ & All messages were found useful. & "All were useful in one way or another." \\
\hline $\begin{array}{l}\text { Least-breastfeeding not applicable } \\
(\mathrm{HI}=5, \mathrm{PR}=7)\end{array}$ & $\begin{array}{l}\text { Breastfeeding information did not apply to } \\
\text { the participant. }\end{array}$ & $\begin{array}{l}\text { "Had to stop breastfeeding before } 6 \text { months due to MD's order, } \\
\text { this message didn't apply." }\end{array}$ \\
\hline $\begin{array}{l}\text { Least-breastfeeding known }(H=3 \text {, } \\
P R=7)\end{array}$ & $\begin{array}{l}\text { Participants already knew the } \\
\text { breastfeeding information. }\end{array}$ & "I already knew." \\
\hline
\end{tabular}


behavior or weight. The outcomes of the trial have been reported in a separate publication. In addition, due to the capabilities of the web-based text messaging platform, once a text message question was delivered, participants were allowed to respond for the following $12 \mathrm{~h}$ only. After the 12-h window, the server did not record responses. The number of responses to the two text questions investigated in this study was low (HI: 37.8\%; PR: $27.9 \%)$ but it is possible that additional delayed responses were not recorded by the server. Similarly, some messages were categorized by the server as "sent-awaiting confirmation" as some phone carriers did not allow delivery status to be known. In these cases, to ensure that participants were receiving the messages, research staff monitored participants' activity and contacted them if "sent-awaiting confirmation" appeared repeatedly. Messages that were categorized as "bounced" were resent and the participant was contacted if bounced messages occurred repeatedly. In Puerto Rico, a problem requiring an additional server for two popular phone carriers caused four participants to receive only $28-67 \%$ of messages, as reported previously [31]. Finally, some participants $(n=26)$ were not reachable for the followup visit despite efforts to contact them by phone call, text message, email, or voicemail.

\section{Conclusion}

Reflected by participant retention, measures of satisfaction, and reports of behavior change, the text messagebased intervention was found to be acceptable. These results may be used in the further development of text message-based interventions and may inform strategies for childhood obesity prevention. For example, these results could contribute to the development of new mHealth programs at WIC clinics aimed at educating mothers about breastfeeding and other feeding practices. Further research is needed to determine whether such programs may translate into a population-based reduction in childhood obesity.

\section{Abbreviations \\ BMI: Body mass index; mHealth: Mobile health; NHOPI: Native Hawaiian or other Pacific Islander; TFA: Theoretical framework of acceptability; WHO: World Health Organization; WIC: Special Supplemental Nutrition Program for Women, Infants, and Children}

\footnotetext{
Acknowledgments

The authors acknowledge Linda Chock (Branch Chief), Iris Takahashi (Clinic Operations Section Chief), Laura Morihara (Wahiawa WIC Coordinator), Wendy Baker (Wahiawa WIC Office Assistant), Jean Kanda (Leeward WIC Coordinator), Dawn Fujimoto-Redoble (Leeward WIC Nutritionist), and Christina Mariano (Pearl City WIC Coordinator) from the Hawai'i Department of Health WIC Services Branch. They also acknowledge the Puerto Rico WIC Program, including Dana Miró (Executive Director), Blanca Sastre (Interim supervisor of Nutrition and Lactation Division), Alexandra Reyes (Nutrition Education Coordinator), Iris Roldan (Breastfeeding Coordinator), Ivelisse Bruno (Breastfeeding Peer Support Coordinator), Sherley M. Panell (Nutrition Supervisor in Plaza las Americas WIC (linic) and her team, and Marta Meaux
}

(Nutrition Supervisor in Trujillo Alto WIC Clinic) and her team. They also thank the WIC participants and undergraduate and graduate research assistants.

\section{Authors' contributions}

$C G$, JB and CP developed the research objectives and plan. JB and CP oversaw the research teams in Hawai'i and Puerto Rico, respectively. CG and $\mathrm{RG}$ analyzed the data. $\mathrm{CP}, \mathrm{MC}$, and JB provided guidance for data analysis and interpretation. CG and JB wrote the manuscript. All authors read and approved the final manuscript.

\section{Authors' information}

CG is an instructor in the Department of Human Nutrition, Food and Animal Sciences at the University of Hawaii at Manoa. Her research experiences include the areas of maternal and children's health, obesity prevention, cancer, diabetes, and natural product pharmacokinetics.

$\mathrm{CP}$ is an associate professor in the Department of Dietetics \& Nutrition in the Robert Stempel College of Public Health \& Social Work at Florida

International University. She has conducted several trials in adolescents and adults to determine the effects of dietary supplements and functional foods on bone and body composition. She has developed and validated food frequency questionnaires to evaluate intake and tested interventions using technology for obesity prevention. Her research is currently focused on studying the role of diet and physical activity on obesity and weight gain in infants, children, adolescents, and pregnant women.

MC is a Professor of the Endocrinology Section, Department of Pediatrics at the University of Puerto Rico Medical Science Campus and the Dental and Craniofacial Genomics Core of the School of Dental Medicine. Her work includes clinical trials and educational programs targeting comprehensive prevention of non-communicable diseases across the lifespan. Her work has focused on the developmental origins of non-communicable diseases and clinical outcomes related to arboviral infections in utero.

RG completed a Master of Nutritional Science in the Medical Sciences Campus of the University of Puerto Rico. Currently, he is completing the Pharm Doctorate.

$J B$ is an Associate Professor in the Department of Human Nutrition, Food and Animal Sciences at the University of Hawai'i at Mānoa. She has an interest in obesity prevention and health promotion in diverse populations. Much of her current work centers on nutrition education and development of tools to evaluate nutrition education programs aimed at promoting healthy eating. Her previous work at the University of California, Davis involved the development of two tools, a food behavior checklist and physical activity questionnaire, to be used in the low-income Spanishspeaking community in the U.S. to evaluate nutrition education interventions.

\section{Funding}

This work was supported by the National Institute of Minority Health and Health Disparities (NIMHD), of the National Institutes of Health under award number U54MD008149. Infrastructure support was also provided in part by the National Institute on Minority Health and Health Disparities RCMI Grant: 8G12MD007600. This research was supported in part by grant U54MD007584 (RMATRIX) from the National Institute on Minority Health and Health Disparities (NIMHD) of the National Institutes of Health (NIH). The study sponsor had no involvement in study design, data collection, analysis and interpretation, in writing the report or in submitting the paper for publication.

\section{Availability of data and materials}

Data available from the corresponding author upon request (with names redacted)

\section{Ethics approval and consent to participate}

The institutional review boards at the University of Hawai'i at Manoa and University of Puerto Rico approved study procedures. Written informed consent was obtained prior to data collection.

\section{Consent for publication}

not applicable.

Competing interests

The authors declare that they have no competing interests. 


\section{Author details}

'Department of Human Nutrition, Food and Animal Sciences, College of Tropical Agriculture and Human Resources, University of Hawai'i at Mānoa, Agricultural Sciences 216, 1955 East-West Rd, Honolulu, HI 96822, USA. ${ }^{2}$ Dietetics and Nutrition Department, Robert Stempel College of Public Health \& Social Work, Florida International University, 11200 SW 8th Street, AHC 5-313, Miami, FL 33199, USA. ${ }^{3}$ Dental and Craniofacial Genomics Unit, Endowed Health Services Research Center, Medical Sciences Campus, University of Puerto Rico, PO Box 365067, San Juan, PR 00936-5067, USA. ${ }^{4}$ Nutrition Program, Graduate School of Public Health, Medical Sciences Campus, University of Puerto Rico, PO Box 365067, San Juan, PR 00936-5067, USA.

Received: 19 April 2019 Accepted: 2 August 2019

Published online: 13 August 2019

\section{References}

1. Kumar S, Kelly AS. Review of childhood obesity: from epidemiology, etiology, and comorbidities to clinical assessment and treatment. Mayo Clin Proc. 2017;92:251-65.

2. Pan L, Blanck HM, Sherry B, Dalenius K, Grummer-Strawn LM. Trends in the prevalence of extreme obesity among US preschool-aged children living in low-income families, 1998-2010. JAMA. 2012;308:2563-5.

3. Taveras E, Gillman M, Kleinman K, Rich-Edwards J, Rifas-Shiman S. Racial/ ethnic differences in early-life risk factors for childhood obesity. Pediatrics. 2010:125:686-95.

4. Oshiro C, Novotny R, Grove J, Hurwitz E. Race/ethnic differences in birth size, infant growth, and body mass index at age five years in children in Hawaii. Child Obes. 2015;11:683-90

5. Thorn B, Tadler C, Huret N, Ayo E, Trippe C. WIC participant and program characteristics final report [Internet]. 2015 [cited 2016 Oct 22]. Available from: http://www.fns.usda.gov/sites/default/files/ops/WICPC2014.pdf

6. Segal L, Rayburn J, Martin A. Childhood obesity trends: the state of obesity [Internet]. State Obes. [cited 2016 Oct 22]. Available from: http:// stateofobesity.org/childhood-obesity-trends/

7. Li C, Kaur H, Choi WS, Huang TT-K, Lee RE, Ahluwalia JS. Additive interactions of maternal prepregnancy BMl and breastfeeding on childhood overweight. Obes Res. 2005;13:362-71.

8. Young B, Johnson S, Krebs N. Biological determinants linking infant weight gain and child obesity: current knowledge and future directions. Adv Nutr. 2012:3:675-86.

9. Spatz D. Preventing obesity starts with breastfeeding. J Perinat Neonatal Nurs. 2014;28:41-50.

10. Kim J, Peterson KE. Association of infant child care with infant feeding practices and weight gain among us infants. Arch Pediatr Adolesc Med. 2008;162:627-33.

11. US Department of Health and Human Services, Office of Disease Prevention and Health Promotion. Healthy People 2020 [Internet]. 2010. Available from: https://www.healthypeople.gov/2020/topics-objectives/topic/maternalinfant-and-child-health/objectives

12. National Center for Chronic Disease Prevention and Health Promotion. Breastfeeding Report Card, Progressing Toward National Breastfeeding Goals: United States 2013-2016 [Internet]. Atlanta, GA; 2016 Aug. Available from: https://www.cdc.gov/breastfeeding/pdf/2016 breastfeedingreportcard.pdf

13. Duan V, Jia Weijun N, Pang X, Bi Y, Wang J, Yin S, et al. Effects of text message intervention on infant growth and anemia at 6 month old. J Hyg Res. 2016;45:226-9 235.

14. Gallegos D, Russell-Bennett R, Previte J, Parkinson J. Can a text message a week improve breastfeeding? BMC Pregnancy Childbirth. 2014;14:374.

15. Horodynski MA, Silk K, Hsieh G, Hoffman A, Robson M. Tools for teen moms to reduce infant obesity: a randomized clinical trial. BMC Public Health. 2015;15:22.

16. Ahlers-Schmidt C, Chesser A, Nguyen T, Brannon J, Hart T, Williams K, et al. Feasibility of a randomized controlled trial to evaluate text reminders for immunization compliance in kids (TRICKs). Vaccine. 2012;30:5305-9.

17. Klasnja P, Pratt W. Healthcare in the pocket: mapping the space of mobilephone health interventions. J Biomed Inform. 2012:45:184-98.

18. Johansen B, Wedderkopp N. Comparison between data obtained through real-time data capture by SMS and a retrospective telephone interview. Chiropr Osteopat. 2010;18:10.
19. Smith A. Americans and text messaging [internet]. Washington, D.C.: Pew Research Center; 2011. p. 1-14. Available from: https:/www.pewinternet. org/2011/09/19/americans-and-text-messaging/

20. Shapiro JR, Bauer S, Hamer RM, Kordy H, Ward D, Bulik CM. Use of text messaging for monitoring sugar-sweetened beverages, physical activity, and screen time in children: a pilot study. J Nutr Educ Behav. 2008;40:385-91.

21. Patrick K, Raab F, Adams MA, Dillon L, Zabinski M, Rock CL, et al. A text message-based intervention for weight loss: randomized controlled trial. J Med Internet Res. 2009;11:e1.

22. Cocosila M, Archer N, Haynes RB, Yuan Y. Can wireless text messaging improve adherence to preventive activities? Results of a randomised controlled trial. Int J Med Inf. 2009;78:230-8.

23. Kerr DA, Harray AJ, Pollard CM, Dhaliwal SS, Delp EJ, Howat PA, et al. The connecting health and technology study: a 6-month randomized controlled trial to improve nutrition behaviours using a mobile food record and text messaging support in young adults. Int J Behav Nutr Phys Act. 2016;13:52.

24. Sekhon M, Cartwright M, Francis JJ. Acceptability of healthcare interventions: an overview of reviews and development of a theoretical framework. BMC Health Serv Res. 2017;17:88.

25. Whittaker R, Merry S, Stasiak K, McDowell H, Doherty I, Shepherd M, et al. MEMO - a mobile phone depression prevention intervention for adolescents: development process and postprogram findings on acceptability from a randomized controlled trial. J Med Internet Res. 2012;14:e13.

26. Brown ON, O'Connor LE, Savaiano D. Mobile MyPlate: a pilot study using text messaging to provide nutrition education and promote better dietary choices in college students. J Am Coll Heal. 2014;62:320-7.

27. Fassnacht DB, Ali K, Silva C, Gonçalves S, Machado PPP. Use of text messaging services to promote health behaviors in children. J Nutr Educ Behav. 2015:47:75-80.

28. Li Y, Wang W, van Velthoven MH, Chen L, Car J, Rudan I, et al. Text messaging data collection for monitoring an infant feeding intervention program in rural China: feasibility study. J Med Internet Res. 2013;15:e269.

29. Centers for Disease Control and Prevention. Growth Charts WHO Child Growth Standards [Internet]. Natl. Cent. Health Stat. [cited 2016 Nov 8]. Available from: http://www.cdc.gov/growthcharts/who_charts.htm\#The\%2 OWHO\%20Growth\%20Charts

30. Banna J, Campos M, Gibby C, Graulau RE, Meléndez M, Reyes A, et al. Multisite trial using short mobile messages (SMS) to improve infant weight in low-income minorities: development, implementation, lessons learned and future applications. Contemp Clin Trials. 2017:62:56-60.

31. Palacios C, Campos M, Gibby C, Melendez M, Lee JE, Banna J. Effect of a multi-site trial using short message service (SMS) on infant feeding practices and weight gain in low-income minorities. J Am Coll Nutr. Forthcoming;

32. Torres R, Soltero S, Trak MA, Tucker CM, Mendez K, Campos M, et al. Lifestyle modification intervention for overweight and obese Hispanic pregnant women: development, implementation, lessons learned and future applications. Contemp Clin Trials Commun. 2016;3:111.

33. McHugh ML. Interrater reliability: the kappa statistic. Biochem Medica. 2012; 22:276-82.

34. Brooke-Sumner C, Petersen I, Asher L, Mall S, Egbe CO, Lund C. Systematic review of feasibility and acceptability of psychosocial interventions for schizophrenia in low and middle income countries. BMC Psychiatry. 2015;15 19. Published 2015 Feb 12. https://doi.org/10.1186/s12888-015-0400-6.

35. Andrews G, Cuijpers P, Craske MG, McEvoy P, Titov N. Computer therapy for the anxiety and depressive disorders is effective, acceptable and practical health care: a meta-analysis. PLoS ONE. 2010;5(10):e13196. Published 2010 Oct 13. https://doi.org/10.1371/journal.pone.0013196.

36. Cole-Lewis $H$, Kershaw $T$. Text messaging as a tool for behavior change in disease prevention and management. Epidemiol Rev. 2010;32:56-69.

37. Evans WD, Wallace JL, Snider J. Pilot evaluation of the text4baby mobile health program. BMC Public Health. 2012;12:1031.

38. Fjeldsoe BS, Marshall AL, Miller YD. Behavior change interventions delivered by mobile telephone short-message service. Am J Prev Med. 2009:36:165-73.

39. Seema N, Patwari AK, Satyanarayana L. Relactation: an effective intervention to promote exclusive breastfeeding. J Trop Pediatr. 1997;43:213-6.

\section{Publisher's Note}

Springer Nature remains neutral with regard to jurisdictional claims in published maps and institutional affiliations. 